\title{
PATOLOGIAS EM VIAS URBANAS: ESTUDO DE CASO NA CIDADE DE VITÓRIA DA CONQUISTA - BAHIA
}

\section{ARTIGO DE REVISÃO}

COSTA, Gabriel Ferreira ${ }^{1}$

GONÇALVES, Carlos Vinícius Rocha ${ }^{2}$

BRITO, Leonice Pereira ${ }^{3}$

FERREIRA, Letícia da Silva ${ }^{4}$

BRITO, Patric Lima ${ }^{5}$

LIMA, Lívia Ramos ${ }^{6}$

COSTA, Gabriel Ferreira. Et al. Patologias em vias urbanas: Estudo de caso na Cidade de Vitória da Conquista - Bahia. Revista Científica Multidisciplinar Núcleo do Conhecimento. Ano 05, Ed. 05, Vol. 13, pp. 05-20. Maio de 2020. ISSN: 2448-0959, Link de acesso: https://www.nucleodoconhecimento.com.br/engenhariacivil/patologias-em-vias

\footnotetext{
${ }^{1}$ Graduando em Engenharia Civil.

2 Graduando em Engenharia Civil.

${ }^{3}$ Graduanda em Engenharia Civil.

${ }^{4}$ Graduanda em Engenharia Civil.

${ }^{5}$ Graduando em Engenharia Civil.

${ }^{6}$ Especialização em Engenharia Rodoviária: Do Estudo De Viabilidade Ao Projeto Executivo. Graduação em Engenharia Civil. Graduação em Enfermagem.
} 


\section{RESUMO}

O pavimento é uma estrutura que está destinada a resistir aos esforços do tráfego de pessoas ou cargas, sendo de grande importância para o desenvolvimento social e econômico do país. Esse trabalho é um estudo de caso realizado na avenida Otávio Santos, localizada na cidade de Vitória da Conquista. Será feita uma análise visual seguida de um relatório fotográfico, tendo como base a realização de um levantamento bibliográfico sobre a constituição dos pavimentos, patologias gerais e patologias encontradas na avenida, de modo a discutir possíveis causas e soluções. Ao longo da vida útil de um pavimento, neste podem surgir patologias causadas por diversos aspectos, sendo necessária a compreensão das patologias para que sejam aplicados reparos adequados. Durante a análise, foi possível identificar que uma patologia comum é a ondulação, e, além disso, existem panelas ou buracos, remendos, trincas em malha tipo couro de jacaré e trincas longitudinais que colocam em risco o deslocamento de pessoas e cargas. Métodos como o uso das técnicas de capa selante, tratamento superficial, lama asfáltica, micro revestimento asfáltico, recapeamento estrutural e fresagem são algumas das alternativas. O presente trabalho busca elucidar a decorrência de patologias, diferenciando por implantação ou manutenção, com enfoque na escolha da melhor metodologia e técnica para recuperação de cada patologia.

Palavras-chave: Pavimento, patologia, causas das patologias.

\section{INTRODUÇÃO}

A qualidade da malha rodoviária de uma cidade tem grande importância para o desenvolvimento local, pois atende os níveis sociais essenciais ao deslocamento de pessoas e no que tange o transporte de produtos. $O$ interesse dessa pesquisa é analisar visualmente o nível de deformações e patologias presentes em um trecho da avenida Otávio Santos, localizada na região central da cidade de Vitória da Conquista - BA. A avenida tem extensão de $1,1 \mathrm{~km}$, com grande concentração de estabelecimentos comerciais, sendo que o setor hospitalar é o mais predominante na via. A geometria permite que tenha um trânsito fluido e constante, ligando a zona sul 
ao centro da cidade. De acordo com Schmidt (2016), deformações existentes nas vias podem ser chamadas de patologias.

Essas anomalias podem surgir por cargas aplicadas provenientes do tráfego de veículos ou por intempéries e fazem com que a rodovia perca a capacidade de fornecer um trânsito confortável, com segurança e fluidez, não cumprindo a função para a qual foi dimensionada. Almeida (2019), afirma que os problemas patológicos causados nas vias estão diretamente ligados à idade do pavimento, volume de tráfego, mal dimensionamento e ausência de gerenciamento, além da carência de manutenção e fiscalização dos órgãos responsáveis no Brasil, entre outras causas que podem impedir o bom funcionamento da rodovia. O diagnóstico correto das patologias encontradas na via é de suma importância, de modo a otimizar os processos de recuperação das anomalias no pavimento.

Detalhar-se-á, com maior precisão, a melhor técnica a ser utilizada para a recuperação do pavimento, indicando os possíveis fatores que ocasionaram os defeitos, e, a partir da revisão bibliográfica, determinar-se-á o método mais adequado para a recuperação. $O$ estudo de caso em questão procura desenvolver uma revisão bibliográfica para ajudar na manutenção de patologias existente na avenida, analisando, de forma minuciosa, os aspectos únicos da deformação. Com ajuda de métodos pré-definidos em normas, visando garantir a integridade do pavimento durante o seu uso, entende-se que a manutenção preventiva contribui com o custo reduzido no processo de recuperação e, ainda, evita possíveis impactos, como acidentes e engarrafamentos no trânsito.

\section{FUNDAMENTAÇÃO TEÓRICA}

\subsection{CLASSIFICAÇÃO E CONSTITUIÇÃO DE PAVIMENTOS}

Nas rodovias, o pavimento é considerado uma superestrutura, composta por sistemas de camadas com espessuras finitas, situado sobre um semi espaço, de acordo com a teoria, ilimitado. Os subleitos destes pavimentos são chamados de infraestrutura ou terreno de fundação do sistema (BRASIL, 2006). O manual acrescenta que o subleito 
no qual são submetidas as cargas impostas pelo tráfego deve ser estudado em relação à uma determinada região de $0,60 \mathrm{~m}^{2}$ e profundidade de $1,50 \mathrm{~m}$. Para Bernucci et al (2008, p. 10):

Pavimento é uma estrutura de múltiplas camadas de espessuras finitas, construída sobre a superfície final de terraplenagem, destinada técnica e economicamente a resistir aos esforços oriundos do tráfego de veículos e do clima, e a propiciar aos usuários melhoria nas condições de rolamento, com conforto, economia e segurança.

A compactação do solo, considerada um ponto indispensável para execução de pavimento, é um processo de estabilização do solo com intuito de reduzir o volume de vazios e melhorar suas características, como a permeabilidade e resistência, conforme o manual de pavimentação do DNIT (BRASIL, 2006 apud PINTO, 2006). Nos pavimentos, o ensaio mais utilizado é o de Califórnia, introduzido por Porter, em 1929, que, em seus estudos, determinou a seguinte sequência 1) determinação da umidade ótima e peso específico máximo; 2) determinação das propriedades expansivas do material, e 3) determinação do Índice de Suporte de Califórnia - ISC , que significa California Bearing Ratio - CBR (CAPUTO, 1996). De acordo com o manual de pavimentação do DNIT (BRASIL, 2006), os pavimentos são classificados em rígidos, flexíveis e semi-rígidos.

\subsubsection{PAVIMENTO RÍGIDO}

Segundo Bernucci (2008), os pavimentos denominados rígidos têm sua estrutura composta por uma placa de concreto, com espessura fixada em função das resistências das placas e das camadas anteriores. O pavimento pode dispor de armadura ou não, conforme a figura 1. Com uma rigidez elevada quando se comparada às camadas inferiores, o pavimento rígido consegue absorver praticamente todas as tensões nele aplicadas (BRASIL, 2006). 
Figura 1: Pavimento Rígido

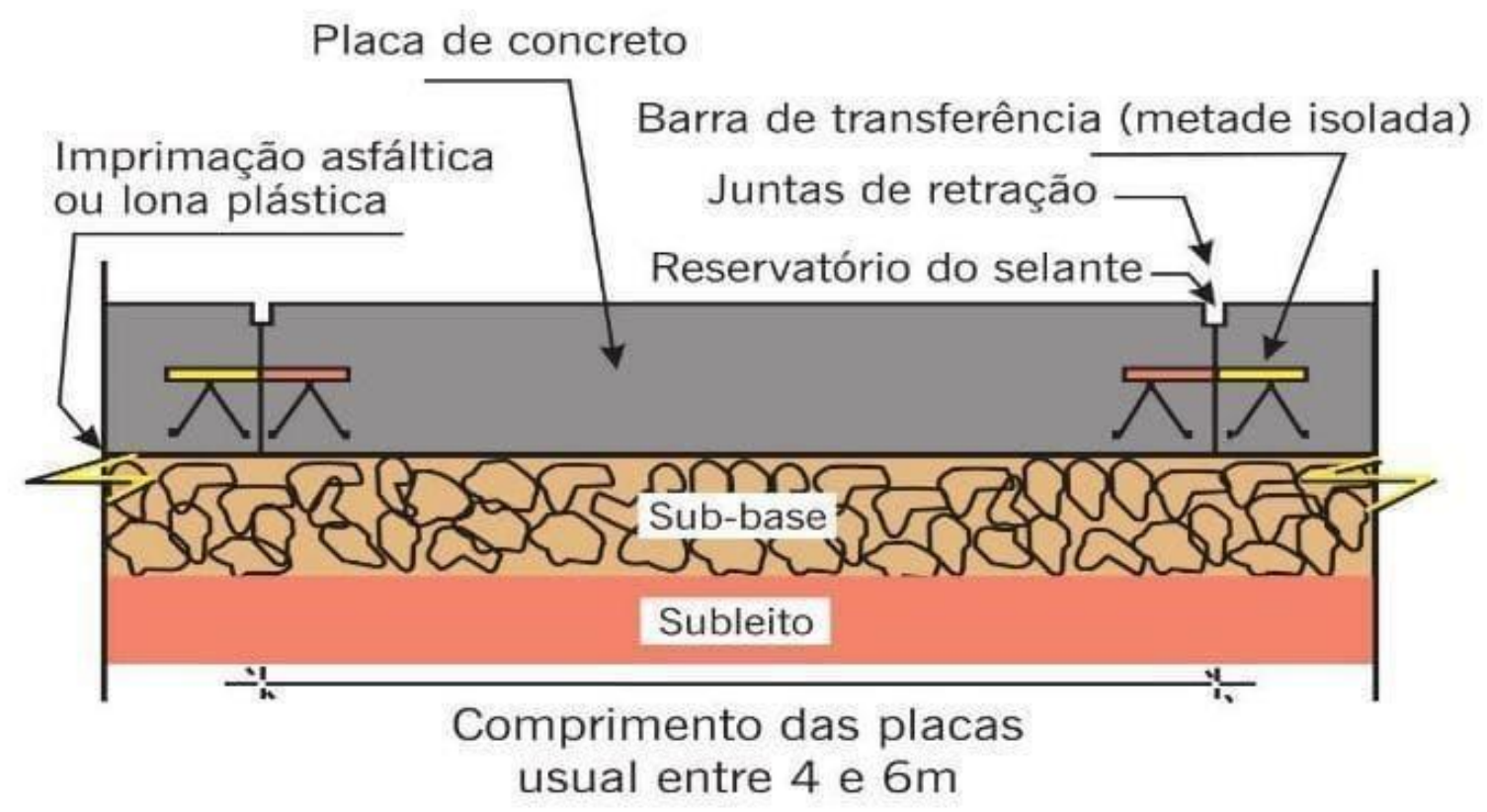

Fonte: Bernucci (2008)

\subsubsection{PAVIMENTOS FLEXÍVEIS}

O pavimento flexível se encontra sob uma base de brita ou pedregulho e coberta por uma camada asfáltica, e, dessa forma, sofre deformações elásticas em todas as camadas sob carregamento aplicado e possui cargas distribuídas em partes equivalentes entre elas. As estruturas das camadas podem ser visualizadas na figura 2 (BRASIL, 2006). 
Figura 2: Pavimento Flexível

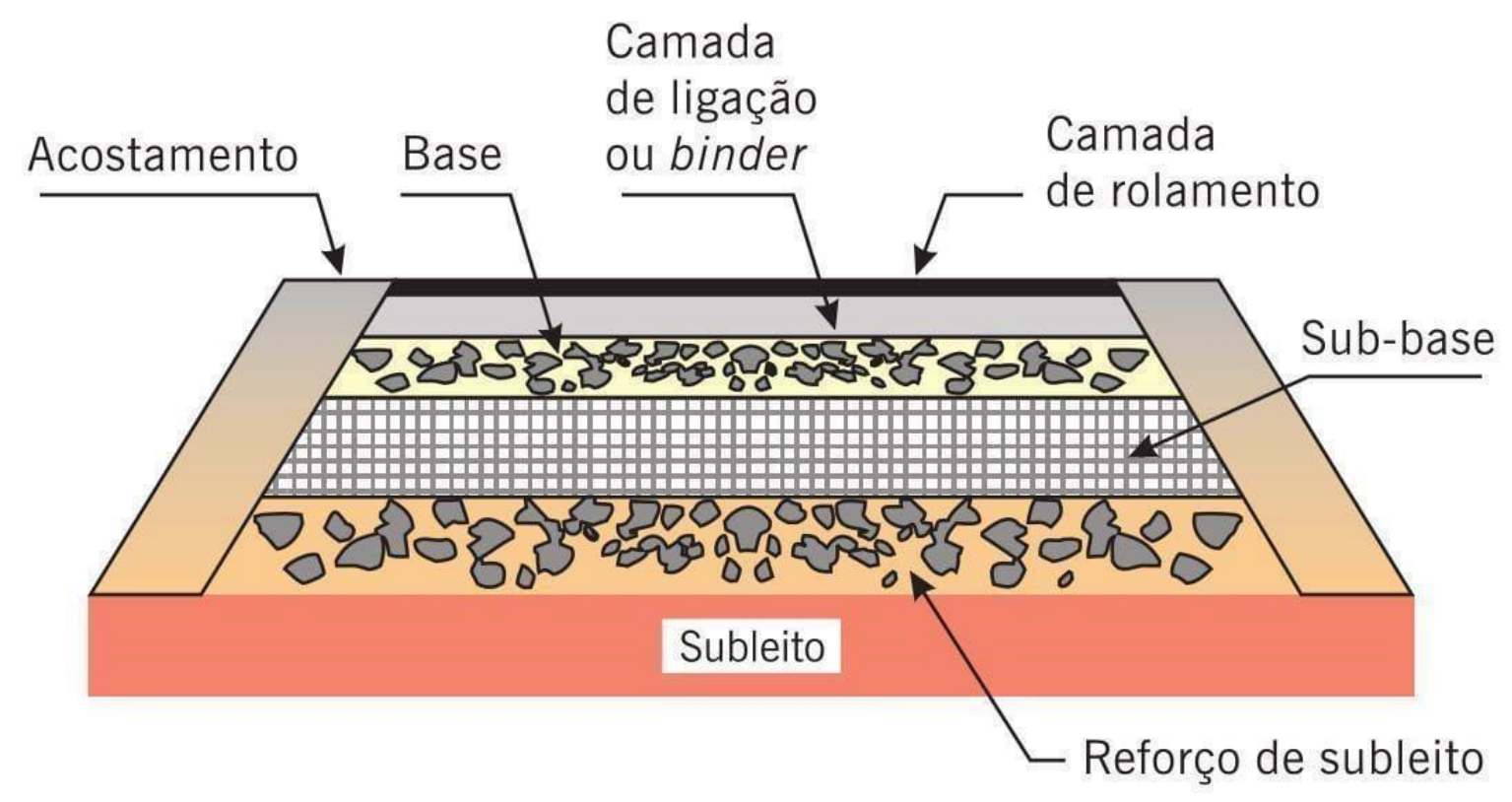

Fonte: Bernucci (2008)

\subsubsection{PAVIMENTO SEMI-RÍGIDOS}

Há, ainda, o pavimento semi-rígido ou semi-flexível. Trata-se de um pavimento asfáltico executado sobre uma camada de solo cimento, cuja superfície é cimentada com auxílio de aglutinantes que tenham propriedades cimentícias (BRASIL, 2006).

\subsection{PATOLOGIAS NOS PAVIMENTOS}

Segundo a norma brasileira DNIT 005 (2003), que aborda sobre a terminologia dos defeitos ou patologias nos pavimentos semi-rígidos e flexíveis, existem diversos tipos de patologia, tais como fendas, corrugação e ondulações transversais, exsudação, afundamentos, panela ou buraco, remendos e desgaste ou desagregação. Estas patologias serão apresentadas a seguir, de acordo com terminologias da norma brasileira DNIT 005 (BRASIL, 2003). 


\subsubsection{FENDA}

A fenda é considerada uma irregularidade na superfície do pavimento que pode se apresentar como fissura ou trinca, dependendo da variação da espessura. As fissuras são fendas capilares que não causam problemas funcionais ao revestimento. Manifestam-se nas posições longitudinais, transversais e oblíquas, apenas perceptíveis com ajuda de aparelhos ou a olho nu com uma distância inferior a 1,50 m. As trincas, por outro lado, possuem espessura maior que as fissuras e são facilmente visíveis a olho nu. Manifestam-se isoladamente ou interligadas. A trinca do tipo interligada divide-se em tipo bloco ou couro de jacaré e a isolada em transversal, longitudinal ou de retração.

\subsubsection{CORRUGAÇÃO OU ONDULAÇÃO TRANSVERSAL}

A ondulação ou corrugação é uma deformação plástica na superfície do pavimento que forma ondas ao longo de sua extensão. Geralmente, este tipo de patologia ocorre pela falta de instabilidade da mistura betuminosa que constitui o revestimento ou base.

\subsubsection{EXSUDAÇÃO}

Exsudação é uma camada de material betuminoso que surge na superfície do pavimento, causada pela migração do ligante em sua superfície.

\subsubsection{AFUNDAMENTO}

O afundamento é caracterizado pelo rebaixamento da superfície do pavimento. É causado pela ação das cargas dos pneu que se manifestam de forma plástica ou a partir da consolidação. O afundamento plástico acontece devido à fluência do revestimento ou do subleito e acompanha o solevamento. $O$ afundamento de consolidação, entretanto, é quando ocorre a consolidação de forma diferencial de uma ou mais camadas do pavimento e não há acompanha o solevamento. Ambos os tipos de afundamento podem ser definidos por local ou trilha de roda e são caracterizados 
por local quando possuem extensão de até $6 \mathrm{~m}$ e trilha de roda por se localizarem ao longo da trilha com extensão acima de $6 \mathrm{~m}$.

\subsubsection{PANELA}

Panela ou buraco é uma cavidade que se forma no revestimento de diversos tamanhos e profundidades. Pode ser causada por diversos fatores, mas o principal é a falta de junção entre as camadas superpostas do pavimento, podendo alcançar camadas inferiores e provocar desagregação.

\subsubsection{REMENDOS}

O remendo se trata de panela ou buraco preenchido com uma ou várias camadas de pavimento, podendo ser um remendo superficial ou profundo. No remendo superficial é feita uma correção no revestimento com material betuminoso no local da panela ou buraco. No remendo profundo, geralmente, realiza-se um corte retangular e, posteriormente, é feita a substituição do revestimento e, em alguns casos, de algumas camadas do pavimento.

\subsubsection{DESGASTE OU DESAGREGAÇÃO}

O desgaste está associado aos esforços causados pelo tráfego e se trata do arrancamento progressivo do agregado da superfície do pavimento, tornando sua superfície áspera.

\subsection{MÉTODOS DE RECUPERAÇÃO}

Silva (2008) destaca que para fazer uma manutenção ou recuperação do pavimento flexível, primeiro deve-se determinar a causa do defeito ou patologia existente, e, após, executar o serviço o tanto quanto possível próximo de sua condição original. A eficiência dos serviços de manutenção se dá pela identificação e reparo das patologias em fases iniciais, pois evita-se a evolução constante que, consequentemente, aumenta os custos da manutenção ou reabilitação do pavimento (ODA, 2003 apud CANDIDO, 2018). O processo de recuperação de pavimento flexível 
está relacionado a duas classes: estrutural e funcional. A camada estrutural diz respeito à diminuição da capacidade de suporte de carga do pavimento e a funcionalidade da segurança do pavimento e trafegabilidade na pista de rolamento (BRASIL, 2006 apud MOTA, 2017).

No projeto de reforço do pavimento, é orientado reavaliar os estudos de tráfego e calcular o número $\mathrm{N}$, sendo $\mathrm{N}$ a análise da quantidade de passagens na via de um veículo com carga padrão de 8,2ft por eixo, acumulado durante toda vida útil projetada, e considerando o tráfego ao qual já foi submetido, de acordo norma rodoviária do Departamento de Nacional de Estradas e Rodagens (DNER, 1979; REVISTA INFRA URBANA, 2014). É necessário, antes da execução do reforço de pavimento no trecho, realizar uma vistoria de trecho para identificar se as alternativas na fase de projeto ainda correspondem tecnicamente às correções das patologias no estado atual, conforme a norma rodoviária do Departamento de Nacional de Estradas e Rodagens (DNER,1979; REVISTA INFRA URBANA,2014).

De acordo com Pessoa Júnior (2015, apud CICHINELLI, 2015), um trecho que possui uma patologia identificada ao tempo de projeto para correção pode se tornar um problema maior quando não resolvida de forma ágil, exigindo, assim, reparos mais profundos, como, por exemplo, reestabilização total da base, o que anteriormente poderia ser resolvido com um processo mais simples.

\subsubsection{RECUPERAÇÃO DE FENDAS}

As técnicas de capa selante e tratamento superficial, geralmente, são utilizadas para correção de fendas, também consideradas fissuras. A capa selante pode ser executada sobre os tratamentos superficiais, considerando o ligante quase que uma emulsão asfáltica. Posteriormente à aplicação ao trecho, é executada a cobertura com agregado miúdo, areia ou pó de pedra e, então, é realizada a compressão. Recomenda-se passar vassoura de arrasto antes da aplicação do ligante na última camada de agregado do tratamento para melhor aderência da emulsão, conforme Bernucci (2008). Segundo Bernucci (2008, p.191), "os chamados tratamentos superficiais consistem em aplicação de ligantes asfálticos e agregados sem mistura 
prévia, na pista, com posterior compactação que promove o recobrimento parcial e a adesão entre agregados e ligantes". Para a correção de desagregação, os mesmos procedimentos supracitados podem ser utilizados, desde que não haja agressão severa da base e da sub-base.

\subsubsection{AFUNDAMENTOS}

Para esse tipo de patologia, duas técnicas são utilizadas para correção. A primeira é a fresagem, que, em processo de remoção, é recomendada antes da execução de camadas do recapeamento, isto é, quando há necessidade de reduzir a energia de propagação de trincas existentes, delongando a sua reflexão em camadas novas. $O$ uso desta técnica demonstra vantagem em relação ao recapeamento, pois o material retirado e triturado é reaproveitado nesse processo, juntamente com a adição de ligantes e rejuvenescedores (BERNUCCI, 2008). De acordo com Bernucci (2008, p. 188):

Fresagem é a operação de corte, por uso de máquinas especiais, de parte ou de todo o revestimento asfáltico existente em um trecho de via, ou até englobando outra camada do pavimento, como forma de restauração da qualidade ao rolamento da superfície, ou como melhoria da capacidade de suporte.

A outra técnica utilizada é o recapeamento estrutural que consiste na aplicação de uma ou mais camadas asfálticas sobre a estrutura do pavimento existente, as quais são responsáveis pelo aumento da capacidade e correção de possíveis saliências existentes no pavimento (DNER, 2006; YOSHIZANE, 2005 apud NETTO, 2013). Para correção de ondulações, corrugações e exsudação, pode ser aplicada essa mesma técnica.

\subsubsection{REMENDOS}

Para execução dos remendos, as condições climáticas são consideradas relevantes, pois é indicado o uso de pré-misturados à frio (PMF), quando emergenciais. Para 
casos permanentes, é necessário uso do concreto betuminoso usinado à quente, o que exige a recuperação da base e sub-base. No processo de correção, é realizado um corte com ângulo de $90^{\circ}$ no revestimento, evitando a fuga e imprimindo-o não só no local remendado, mas em torno do mesmo para garantir selagem de possíveis trincas. Os remendos são compostos por métodos de restauração mais utilizados em manutenção de vias, considerando que todo pavimento, em algum momento, irá apresentar patologias oriundas da trafegabilidade, o que implica reparos de instalações, conforme Guerra (2008 apud ROCHA; COSTA, 2010). Para recuperação da pavimentação com buracos, faz-se necessário o uso desta mesma técnica.

\section{PROCEDIMENTOS METODOLÓGICOS}

A metodologia deste trabalho propõe um estudo de caso sobre a avenida Otavio Santos, Recreio, Vitória da Conquista - BA. Será feita a caracterização e observação da via com auxílio de visitas e de um relatório fotográfico, com vistas a identificar as patologias de pavimentação existentes e recorrentes, quer sejam de ordem de implantação ou manutenção, por meio de métodos de recuperação embasados pela revisão bibliográfica. No que tange a caracterização da via, tem-se que: trata-se de uma avenida de aproximadamente $1.1 \mathrm{~km}$ de extensão (Figura 3), com trechos de pavimentação asfáltica e trecho de pavimentação com paralelepípedos, tendo grande relevância municipal.

A avenida concentra diversas clínicas de atendimento hospitalar que corroboram para um fluxo diário intenso, além de ser uma das vias de ligação do tráfego do sentido zona sul ao centro, escoando o tráfego em ambos os sentidos por se tratar de uma via de mão dupla com estacionamento permitido em ambos os lados, sendo consideradas quatro faixas, com estacionamento em cada extremidade, havendo, ainda, a presença de uma pista de rolamento ao centro nos dois sentidos algo, em torno de 10 a 12 metros de largura, variando em sua extensão. Em termos comparativos, é uma via larga para os padrões do centro da cidade de Vitória da Conquista. 
Figura 3: Localização da Avenida

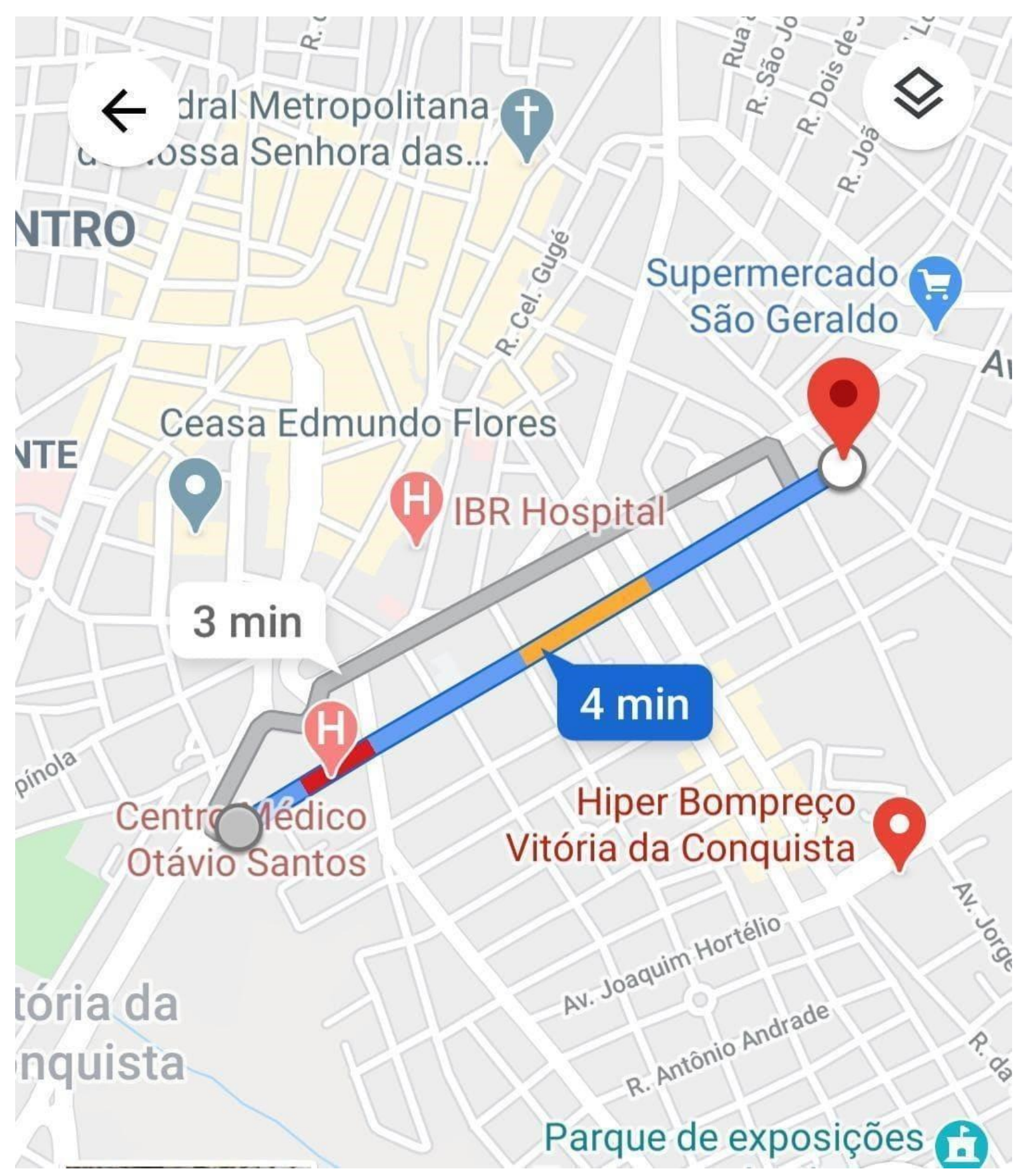

Fonte: Google Maps (2020)

Com o intuito de contextualizar o estudo, vale ressaltar os arredores da via selecionada, bem como a situação de desenvolvimento da cidade na qual ela está inserida. Dados da Prefeitura Municipal de Vitória da Conquista (PMVC), 
disponibilizados pelo portal online da prefeitura, referentes aos anos de 2017 e 2018, relatam que foram pavimentados um total de 8.508 metros de ruas e avenidas em um período de 10 meses. No período total, foram mais de 19 mil metros de vias asfaltadas, recapeadas e reestruturadas, abrangendo 21.344 metros de ruas beneficiadas no período. Observa-se, a partir do presente estudo de caso, a forma com a qual foi feita a execução desse serviço a partir da amostra selecionada, como será demonstrado nas figuras.

Após a realização da observação visual que contemplou um período de 30 dias, entre as datas $26 / 03 / 2020$ a $24 / 04 / 2020$, cujo enfoque esteve essencialmente nos locais que apresentavam patologias visíveis, realizou-se registros fotográficos. Conciliando esses dados com conceitos teóricos, foi observado que em toda a avenida a patologia mais recorrente é a ondulação (Figura 4), causando discrepâncias do nivelamento e modificando a trafegabilidade de veículos na avenida. As medidas tomadas para amenizar o impacto das ondulações observadas foram os remendos e recapeamentos parciais, onde ocorria a pavimentação asfáltica diretamente sobre trechos de pavimentação por paralelepípedos, porém, essas medidas divergem dos métodos bibliográficos recomendados (Figura 5).

Observou-se o surgimento de patologias que tem o caráter de reincidência, seja por intempéries ou desgastes, como trincas longitudinais (Figura 6), cuja pavimentação asfáltica tem um desagregamento e trincas em malha tipo couro de jacaré (Figura 7), além de trechos com descolamento de parte da pavimentação asfáltica (Figura 8), deixando a pavimentação de paralelepípedos abaixo dela aparente. 


\section{MULTIDISCIPLINARY SCIENTIFIC JOURNAL

Figura 4: Trecho da via que apresenta ondulação

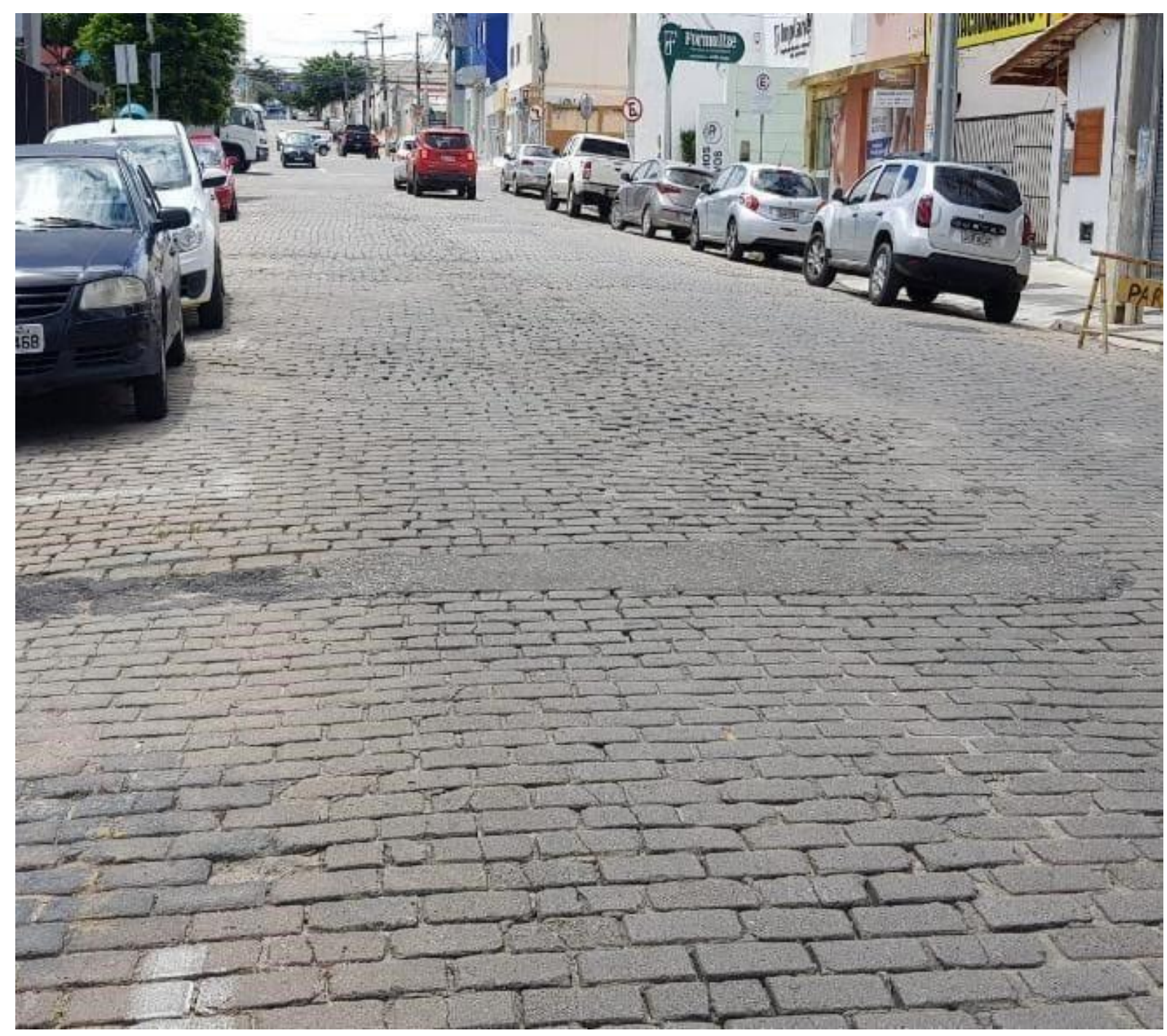

Fonte: Elaborado pelos autores (2020) 
Figura 5: Remendos executados para nivelamento das ondulações.

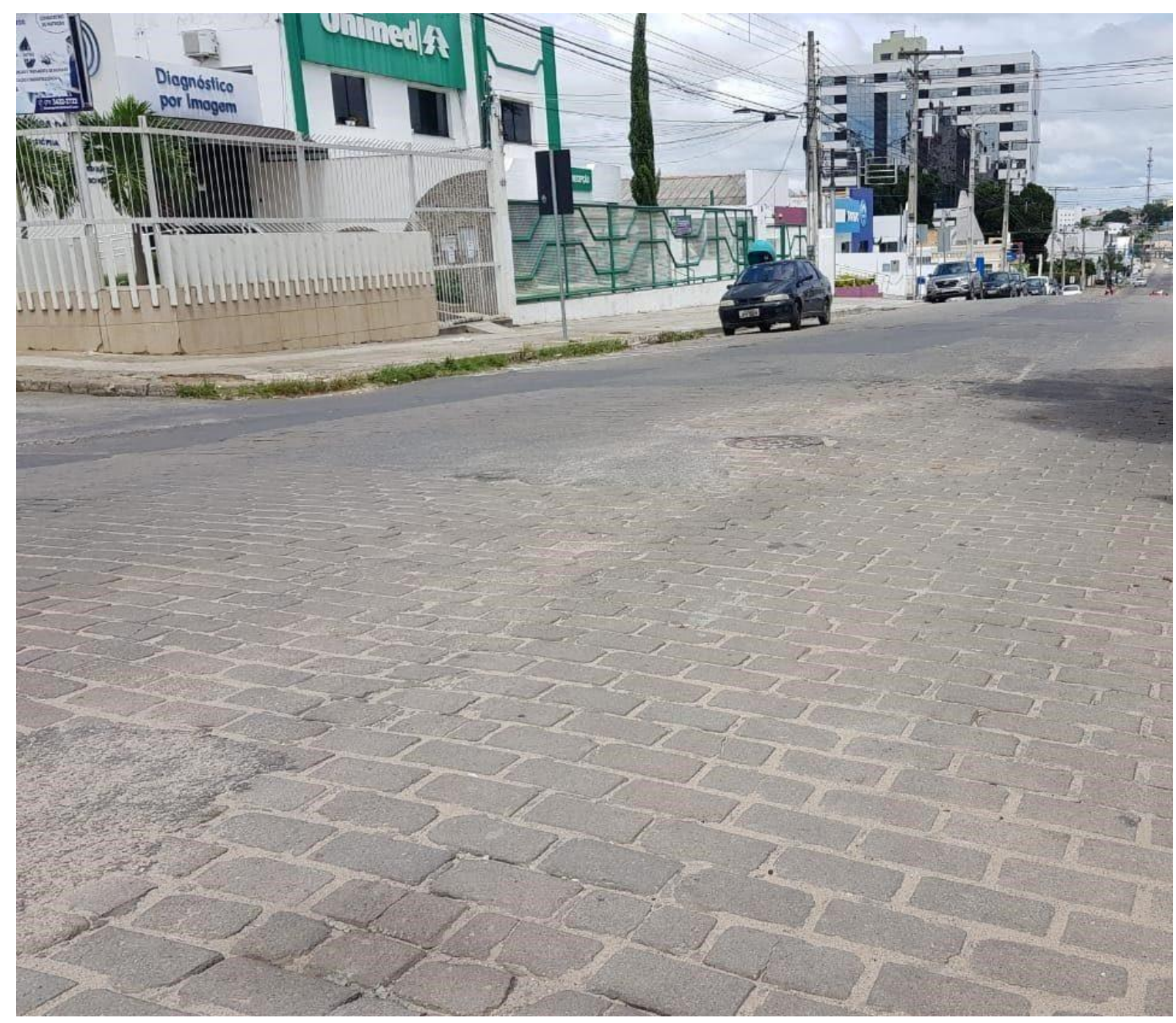

Fonte: Elaborado pelos autores (2020) 
Figura 6: Trincas longitudinais e desagregação na pavimentação asfáltica

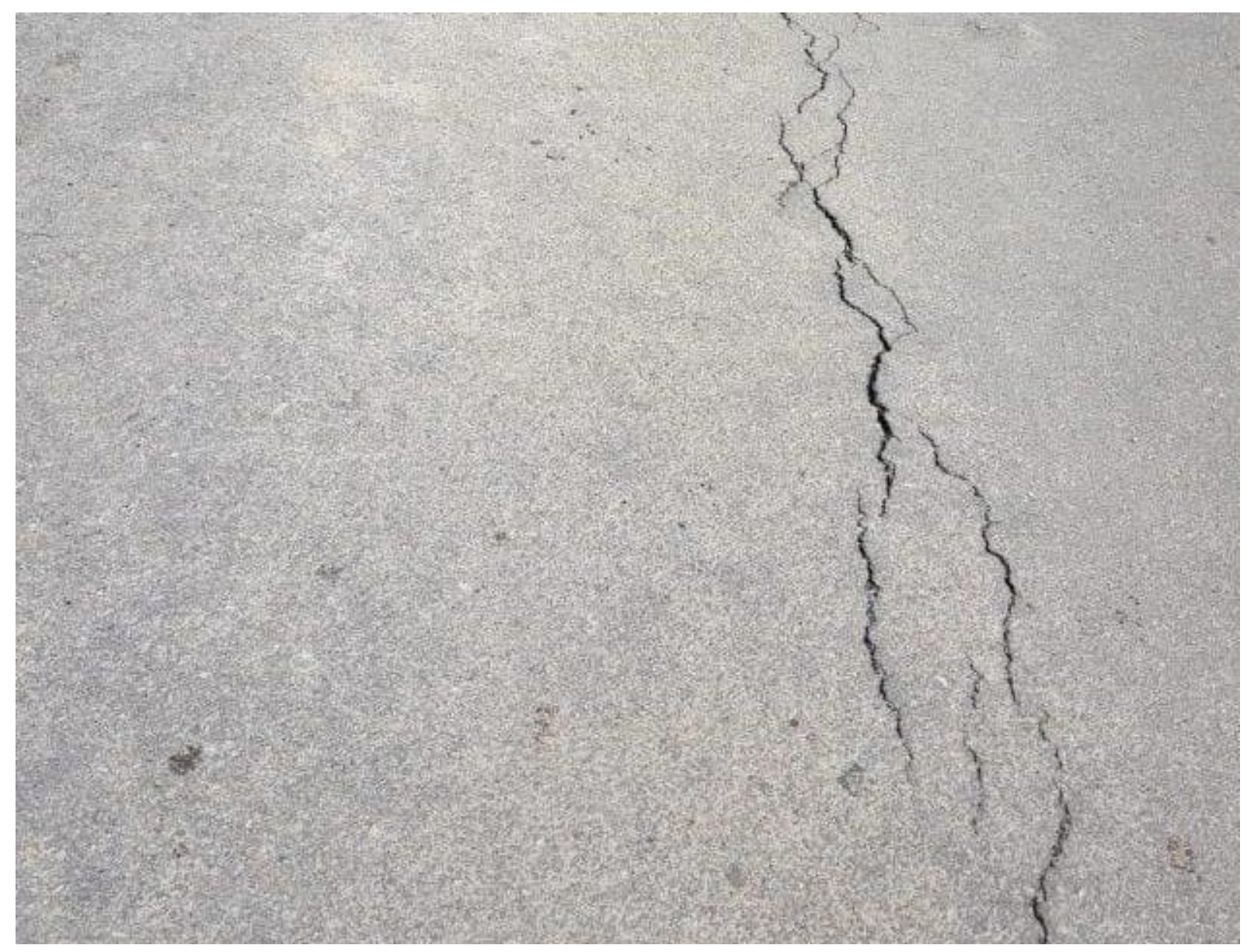

Fonte: Elaborado pelos autores (2020) 
Figura 7: Trincas em malha tipo couro de jacaré

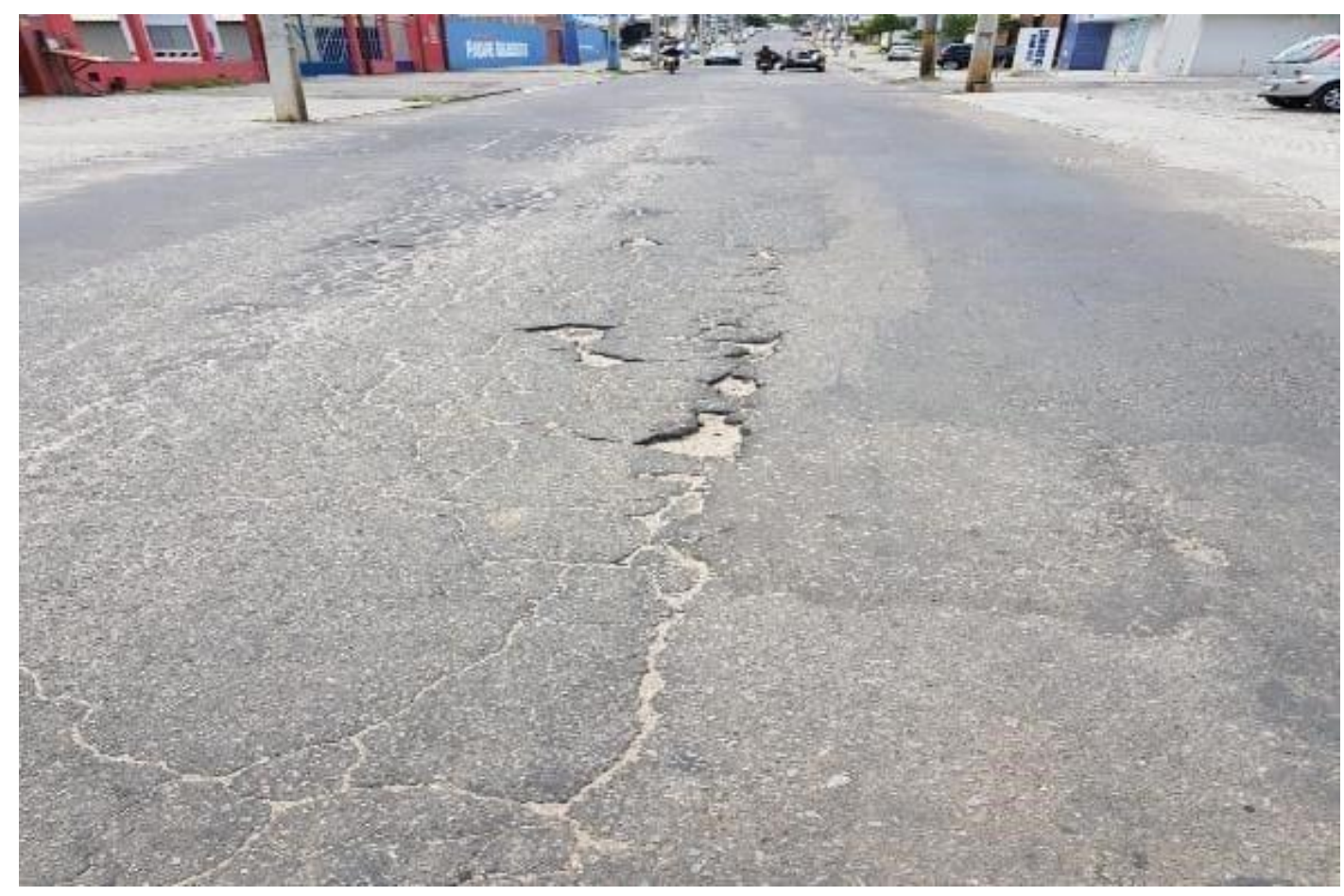

Fonte: Elaborado pelos autores (2020)

Figura 8: Recapeamento sobre camada de paralelepípedos

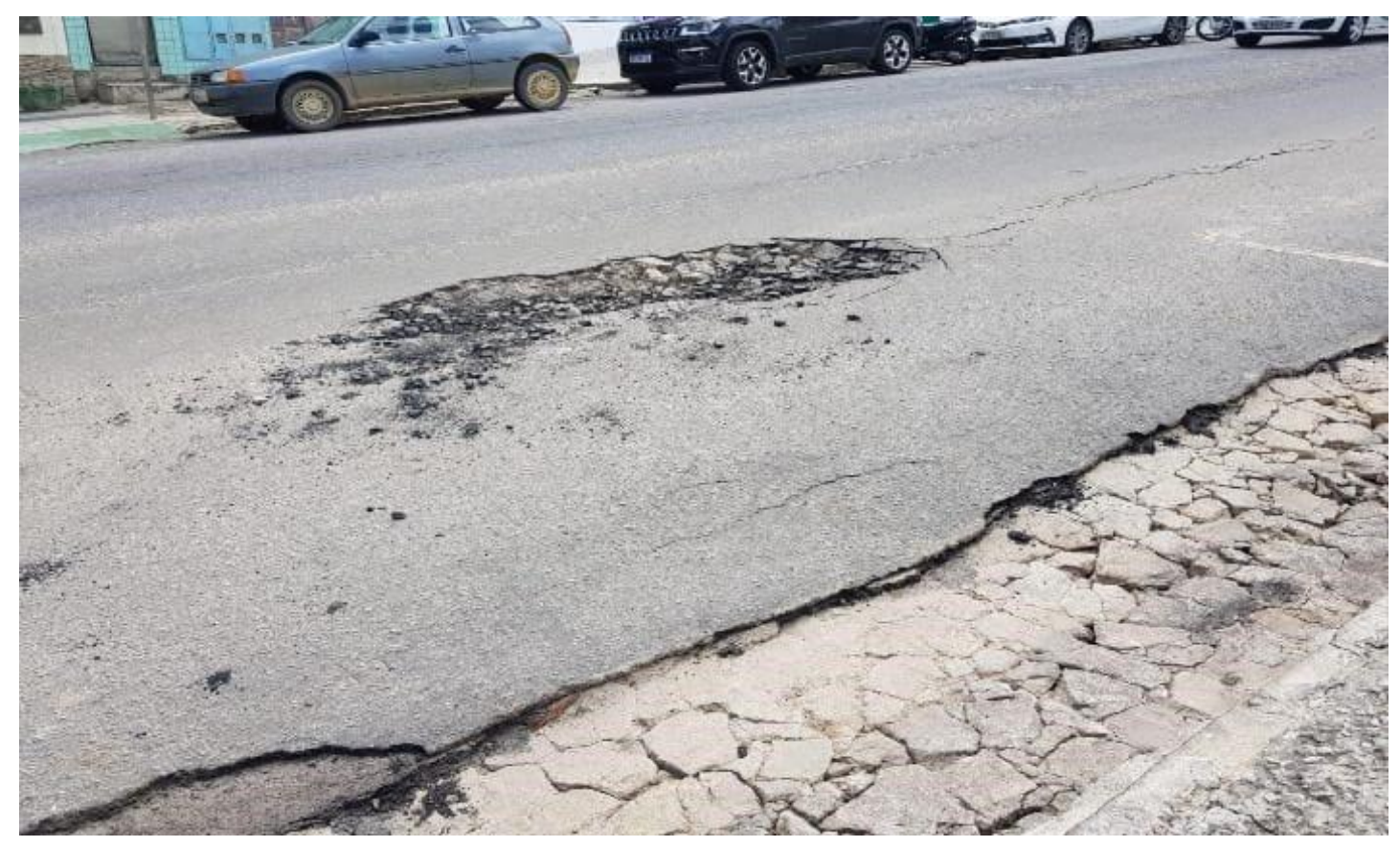

Fonte: Elaborado pelos autores (2020)

RC: 50725

Disponível em: https://www.nucleodoconhecimento.com.br/engenharia-civil/patologias-em-vias 
Intempéries, como períodos de fortes chuvas que a cidade de Vitória da Conquista está sujeita em determinadas épocas do ano, podem produzir um crescimento em número e em proporção das patologias. Correlaciona-se fatores como chuvas, manutenção e implantação ao agente de multiplicação de uma patologia presente e complicação da mesma. Para efeito de análise, toma-se o exemplo de uma obra de recuperação feita nessa mesma via, onde um buraco (Figura 9) que se formou na mesma no dia 30/03/2020 foi revitalizado, houve, no entanto, a reincidência da patologia no local passados 15 dias. Observou-se a formação de um afundamento abrangente (Figura 10), além de agravamento do buraco (Figura 11), a reincidência foi recuperada no dia 20/04/2020 (Figura 12). O retorno patológico pode comprometer a estrutura da via em escala maior do que a inicial, trazendo complicações da patologia e surgimento de ramificações da mesma.

Figura 9: Panela reduzindo área de tráfego na via

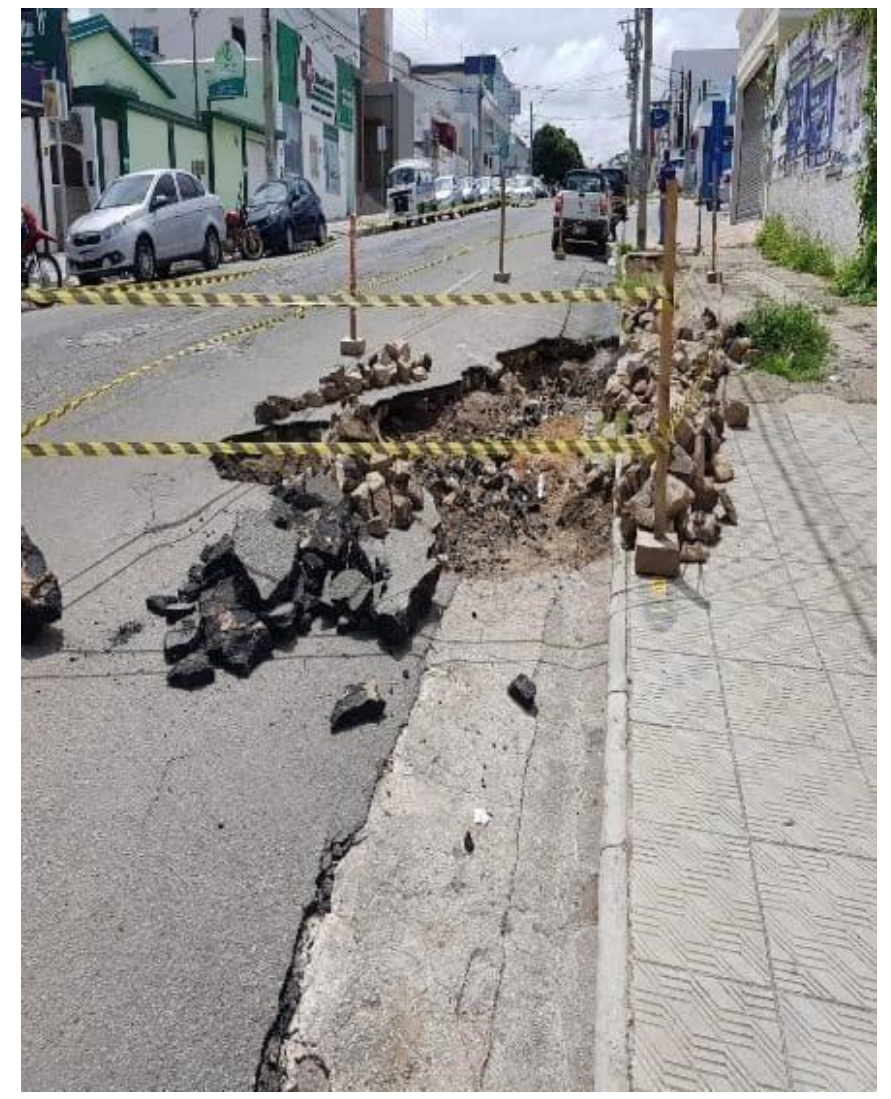

Fonte: Elaborado pelos autores (2020) 
Figura 10: Remendo e afundamento da patologia reincidente

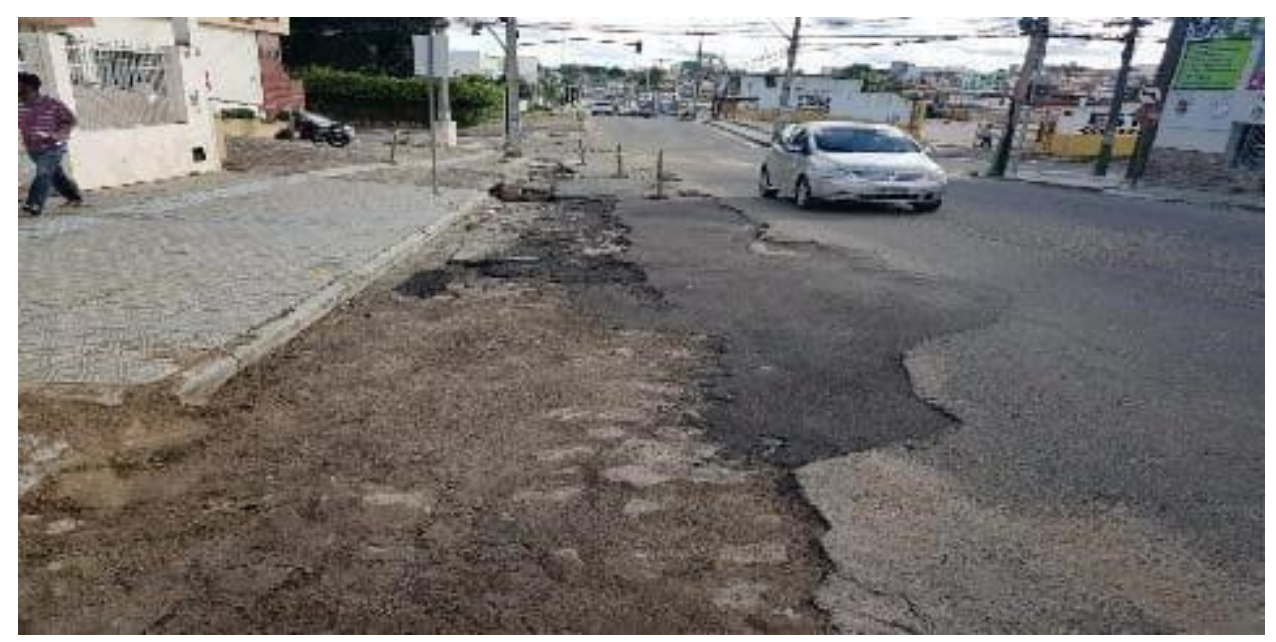

Figura 11: Buraco e afundamento

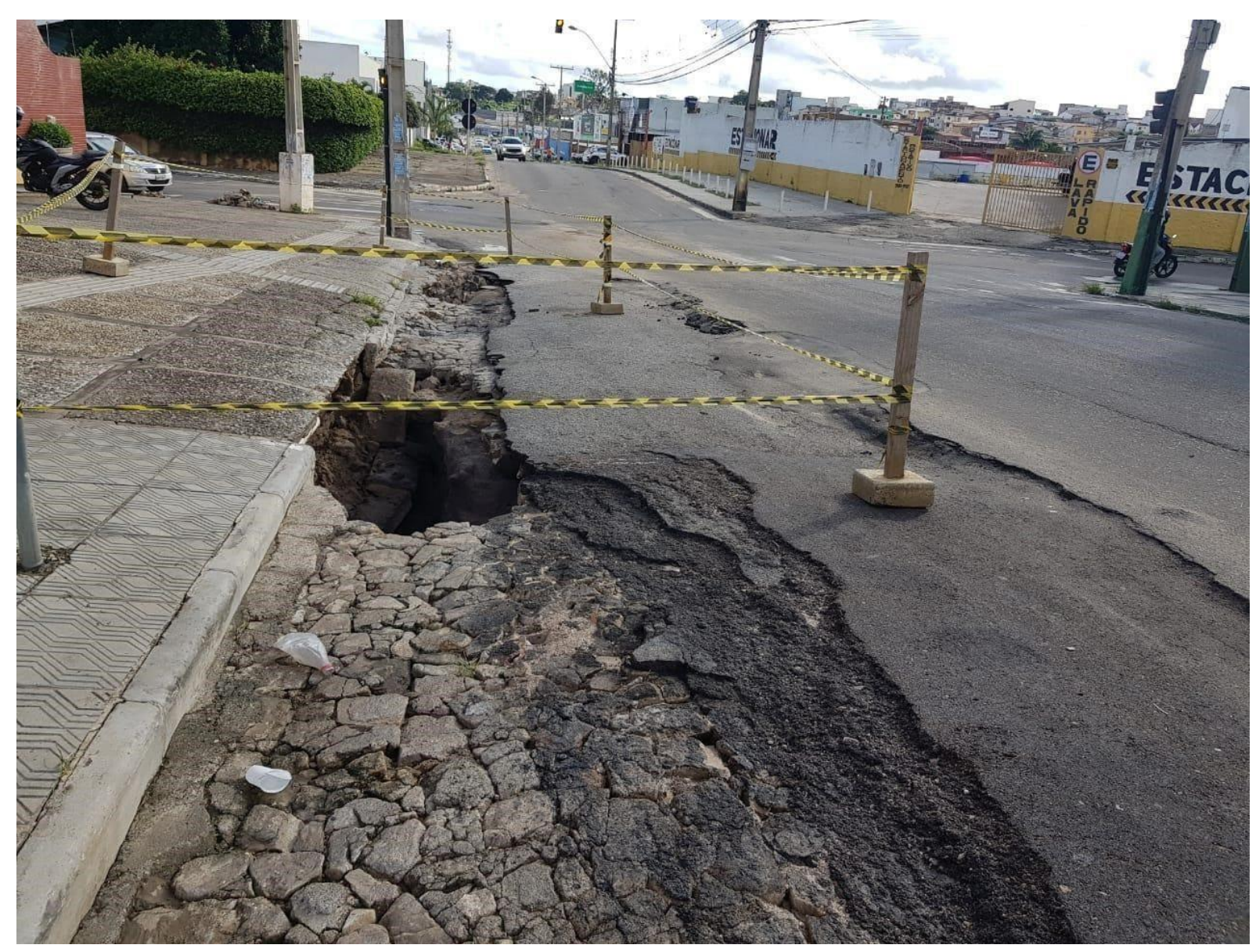

Fonte: Elaborado pelos autores (2020) 
Figura 12: Patologias recuperadas

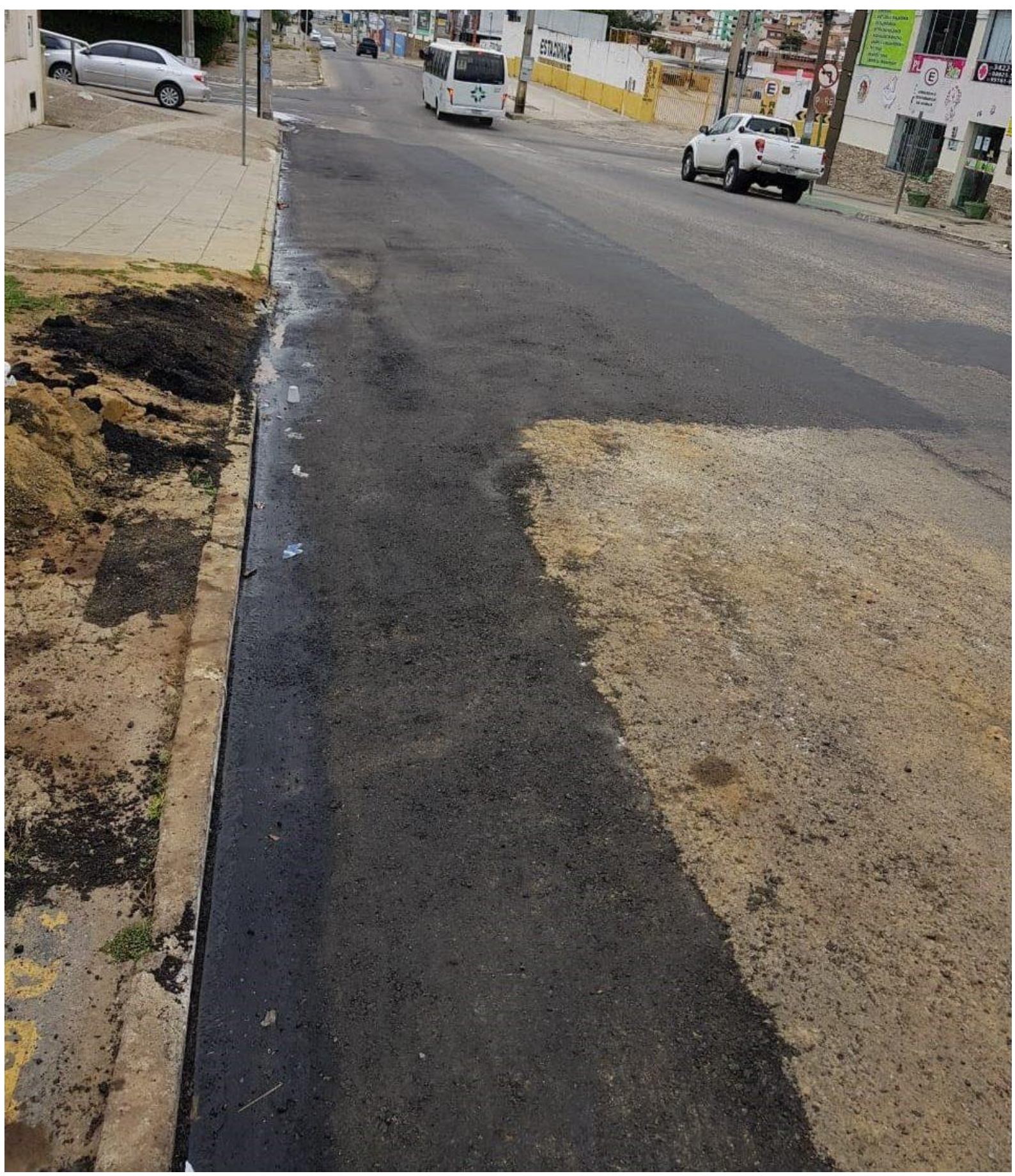

Fonte: Elaborado pelos autores (2020) 


\section{CONSIDERAÇÕES FINAIS}

A pavimentação de vias depende de diversos fatores. A bibliografia do tema é sobressalente neste aspecto ao indicar rigorosos padrões de qualidade a serem seguidos no que tange a implantação, desde a preparação de bases e subleitos do solo até a utilização de materiais adequados e de boa qualidade. Este artigo abordou um estudo de caso realizado após uma revisão bibliográfica para embasamento do tema escolhido. Pôde-se apontar parâmetros necessários para a pavimentação, além de traçar um panorama de diversas patologias gerais, bem como as existentes na via observada. Com o estudo de caso, pôde-se notar a inobservância de alguns fatores que promovem a qualidade geral, como o caso da patologia de ondulação que indica erros na preparação das camadas bases que fundamentam a pavimentação, fator de destaque também nos recapeamentos que foram executados diretamente sobre trechos de paralelepípedos, fazendo, assim, uma correlação entre a existência das patologias, bem como das suas reincidências que foram observadas por meio deste.

Com essa revisão bibliográfica pôde-se trabalhar com os métodos específicos voltados à recuperação para cada patologia apresentada. Uma solução recomendada para a avenida Otávio Santos seria a retirada da atual pavimentação para execução do reforço estrutural com enfoque na compactação, podendo ser implantado um pavimento rígido ou um pavimento flexível. Leva-se em conta, nesses casos, o orçamento disponível, porém, ambos, desde que bem executados, podem atendem as solicitações. No que tange os processos de manutenção da pavimentação, há dois tipos a serem considerados. No primeiro caso há um método incisivo e à curto prazo mais custoso que busca sanar definitivamente os problemas, e, no segundo caso, temos métodos mais simples que podem ou não ser paliativos. Destaca-se que a pavimentação é uma questão de grande importância e que possui etapas de procedimentos complexos que devem ser devidamente observados com o intuito final de promover ao usuário conforto e segurança. 


\section{REFERÊNCIAS}

ALMEIDA, C. da. S. Patologia em vias urbanas: estudo de caso na cidade de Maceió - AL. 2019. 36f. Trabalho de Conclusão de Curso (Graduação em Engenharia Civil) Centro Universitário CESMAC, Maceió, 2019.

BERNUCCI, L. B. et al, Pavimentação Asfáltica: formação básica para engenheiros. $1^{1}$ ed. Rio de Janeiro: Petrobrás ABEDA, 2008.

BRASIL, Departamento Nacional de infraestrutura de transportes. Diretoria de planejamento e pesquisa. Coordenação geral de estudos e pesquisa. Instituto de pesquisas rodoviárias. Manual de pavimentação. Rio de Janeiro, 2006

CAPUTO, H. P. Mecânica dos solos e suas aplicações. $6^{\underline{a}}$ ed. Rio de Janeiro: LTC Editora, 1996.

CANDIDO, K. R. S. et al. Análise do Método de Fresagem como Reciclagem dos Pavimentos. Maceió: Centro Universitário - CESMAC, 2018.

DNER, Projeto de Restauração de Pavimento. São Paulo, 2006.

LEITE, F. da. C. Comportamento Mecânico de Agregados Reciclados de Resíduo Sólido da Construção Civil em Camadas de Base e Sub-Base de Pavimentos. 2007. 185f. Dissertação (Mestrado em Engenharia de Transportes) - Universidade de São Paulo, São Paulo, 2007.

MAIA, I. M. C. Caracterização de Patologias em Pavimentos Rodoviários. 2012. 77f. Dissertação (Mestrado em Engenharia Civil) - Faculdade de Engenharia Universidade do Porto, Porto, 2012.

PREFEITURA MUNCIPAL DE VITÓRIA DA CONQUISTA. Dados. 2020. Disponível em pmvc.ba.gov.br. Acesso: 29 abr. 2020.

PINTO, C. de. S. Curso básico de mecânica dos solos. Em 16 aulas. $3^{a}$ ed. São Paulo: Oficina de Textos, 2006. 
NETTO, M. R. Estudo de Caso do Pavimento Flexível em Determinados Pontos da Zona Urbana de Alegreste - RS. 2013. 163f. Trabalho de Conclusão de Curso (Graduação em Engenharia Civil) - Universidade Federal do Pampa, Alegrete, 2013.

ROCHA, R. S. da.; COSTA, E. A. L. Patologias de pavimentos asfálticos e suas recuperações-estudo de caso da Avenida Pinto de Aguiar. 2010. Disponível em: https://pt.scribd.com/doc/222438739/Patologias-de-Pavimentos-Asfalticos-e-SuasRecuperacoes. Acesso em: 21 mai. 2020.

SCHMIDT, M. Estudo de patologias em pavimentos asfálticos na cidade de Santa Maria - RS. 2016. 63 f. Trabalho de Conclusão de Curso (Graduação em Engenharia Civil) - Universidade Federal de Santa Maria, Santa Maria, 2016.

SILVA, L. A. Sistema de gerência de pavimentos do DER/SP. 2008. 151 f. Dissertação (Mestrado em Engenharia Civil) - Universidade Estadual de Campinas, Campinas, 2008.

Enviado: Maio, 2020.

Aprovado: Maio, 2020. 